\title{
Effects of two different biogenic emission models on modelled ozone and aerosol concentrations in Europe
}

Jianhui Jiang ${ }^{1}$, Sebnem Aksoyoglu ${ }^{1}$, Giancarlo Ciarelli ${ }^{2}$, Emmanouil Oikonomakis ${ }^{1}$, Imad ElHaddad $^{1}$, Francesco Canonaco ${ }^{1}$, Colin O’Dowd ${ }^{3,4}$, Jurgita Ovadnevaite ${ }^{3,4}$, María Cruz Minguillón ${ }^{5}$, Urs Baltensperger ${ }^{1}$, and André S. H. Prévôt ${ }^{1}$

${ }^{1}$ Laboratory of Atmospheric Chemistry, Paul Scherrer Institute, 5232 Villigen PSI, Switzerland

${ }^{2}$ Laboratoire Inter-Universitaire des Systèmes Atmosphériques (LISA), UMR CNRS 7583, Université Paris Est Créteil et Université Paris Diderot, Institut Pierre Simon Laplace, Créteil, France

${ }^{3}$ School of Physics, Centre for Climate and Air Pollution Studies, Ryan Institute, National University of Ireland Galway, University Road, H91CF50 Galway, Ireland

${ }^{4}$ Marine and Renewable Energy Ireland

${ }^{5}$ Institute of Environmental Assessment and Water Research (IDAEA), CSIC, 08034 Barcelona, Spain

Correspondence to: Sebnem Aksoyoglu (sebnem.aksoyoglu@psi.ch), Jianhui Jiang (jianhui.jiang@psi.ch) 
Table S1. Statistical metrics for model performance evaluation. $N$ is the number of data sample, and $M_{i}$ and $O_{i}$ represent modeled and observed values, respectively.

\begin{tabular}{lr}
\hline Metric & Definition \\
\hline Mean Bias (MB) & $M B=\frac{1}{N} \sum_{i=1}^{N}\left(M_{i}-O_{i}\right)$ \\
Mean Gross Error (ME) & $M G E=\frac{1}{N} \sum_{i=1}^{N}\left|M_{i}-O_{i}\right|$ \\
Root Mean Square Error (RMSE) & $R M S E=\sqrt{\frac{1}{N} \sum_{i=1}^{N}\left(M_{i}-O_{i}\right)^{2}}$ \\
Mean Fractional Bias (MFB) & $M F B=\frac{1}{N} \sum_{i=1}^{N} \frac{2 \cdot\left(M_{i}-O_{i}\right)}{M_{i}+O_{i}}$ \\
Mean Fractional Error (MFE) & $M F E=\frac{1}{N} \sum_{i=1}^{N} \frac{2 \cdot\left|M_{i}-O_{i}\right|}{M_{i}+O_{i}}$ \\
\hline
\end{tabular}




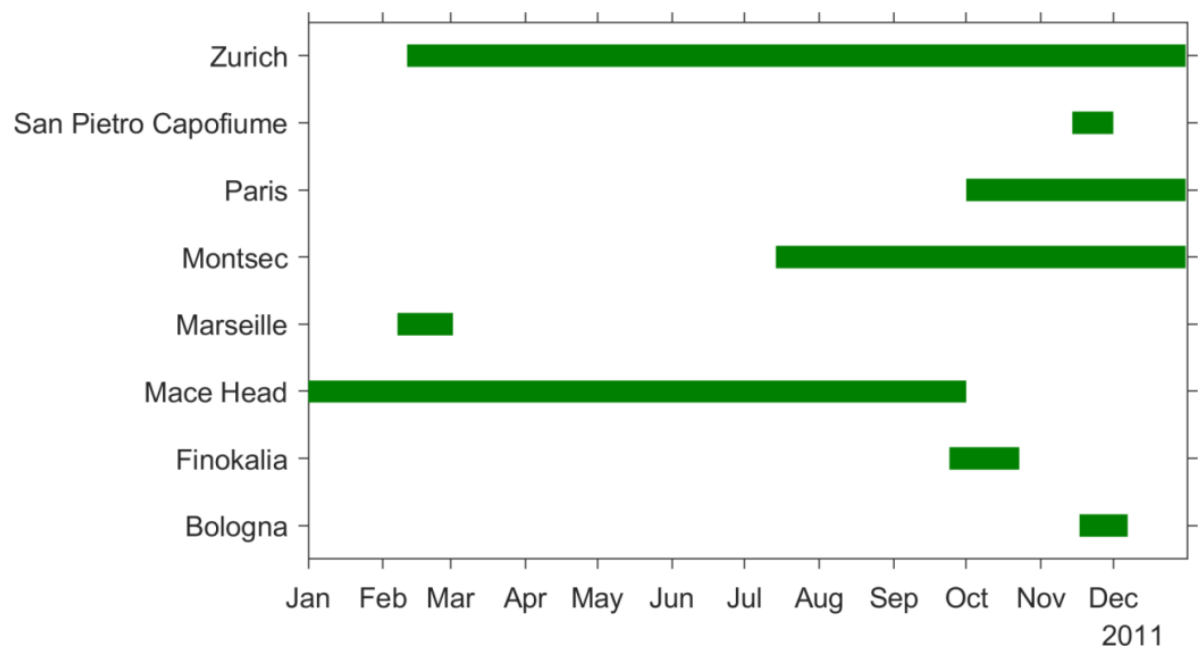

Figure S1. Time span of measurements at 8 ACSM/AMS stations during the simulation period 

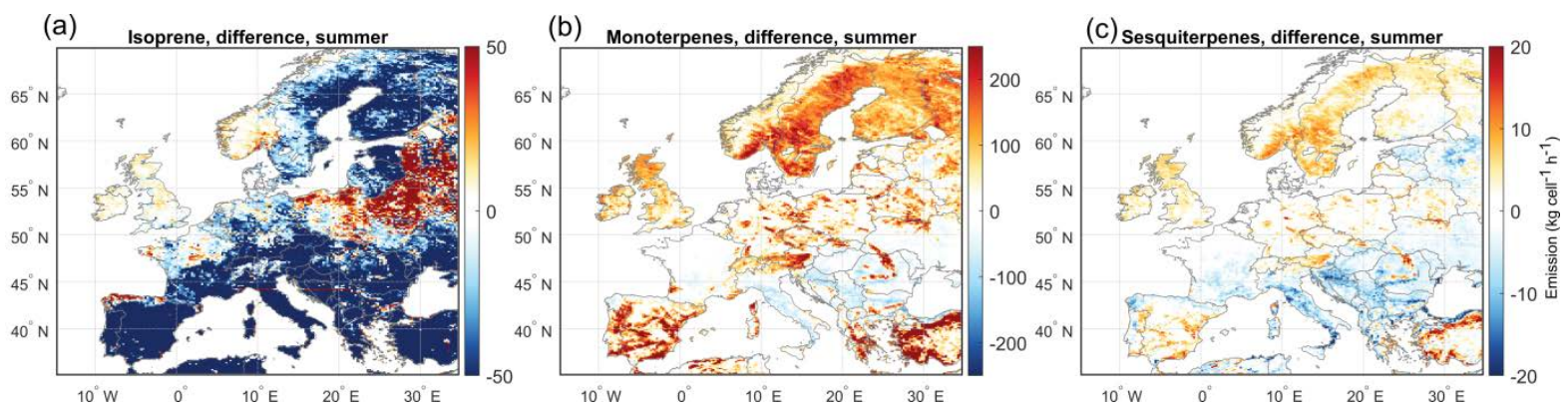

Figure S2. Difference between modelled emissions of isoprene (a), monoterpenes (b) and sesquiterpenes (c) by PSI model and MEGAN in summer.
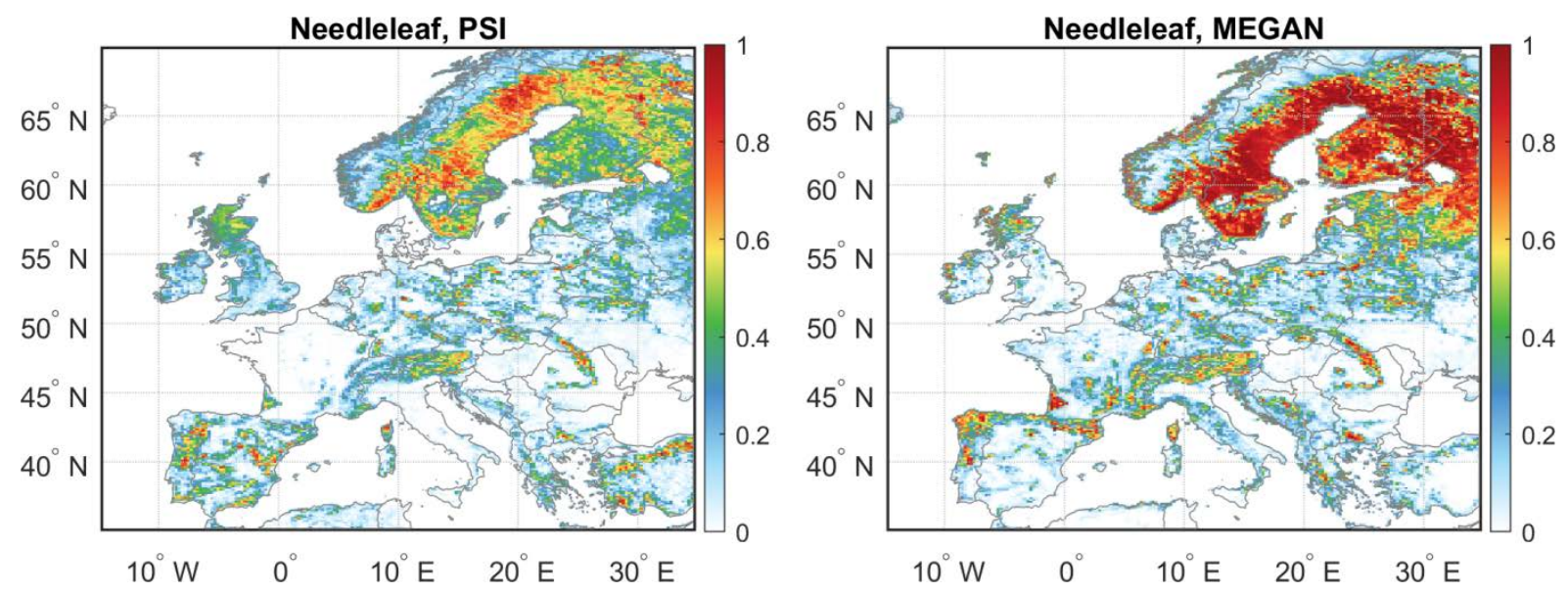

Figure S3. Comparison of fraction of needleleaf forests between PSI (left) and MEGAN (right) landuse inputs. The total fraction for PSI model is the sum of five coniferous trees including Norway spruce, fir, Scots pine, Arolla pine and Larch, while for MEGAN it is the sum of needleleaf evergreen temperate, needleleaf evergreen boreal and needleleaf deciduous boreal trees. 



Figure S4. Backward trajectories ending at UTC 23:00 on $26^{\text {th }}$ March (a) and $4^{\text {th }}$ August (b), 2011 at Mace Head station by NOAA's HYSPLIT atmospheric transport and dispersion modelling system. Trajectories in three level heights were modelled: $100 \mathrm{~m}$ (red), $500 \mathrm{~m}$ (blue), $1000 \mathrm{~m}$ (green). The model vertical velocity approach was used for vertical motion calculation. The Global Data Assimilation System (GDAS) dataset with resolution of 0.5 degree was selected as meteorology input.
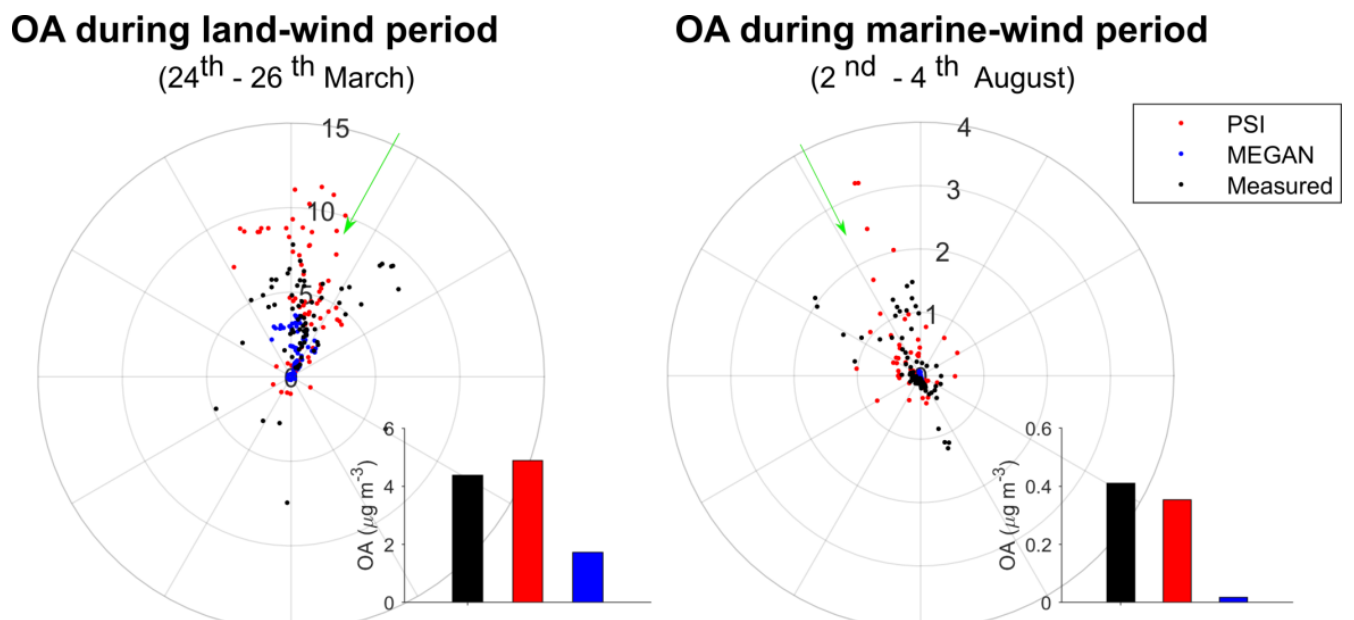

Figure S5. Measured and modelled OA concentration during land-wind and marine-wind dominant periods. Scatter and bar plots are based on hourly and hourly average data, respectively. The angles of polar axes represent modelled wind directions, and the dominant wind directions are marked by green arrows. 

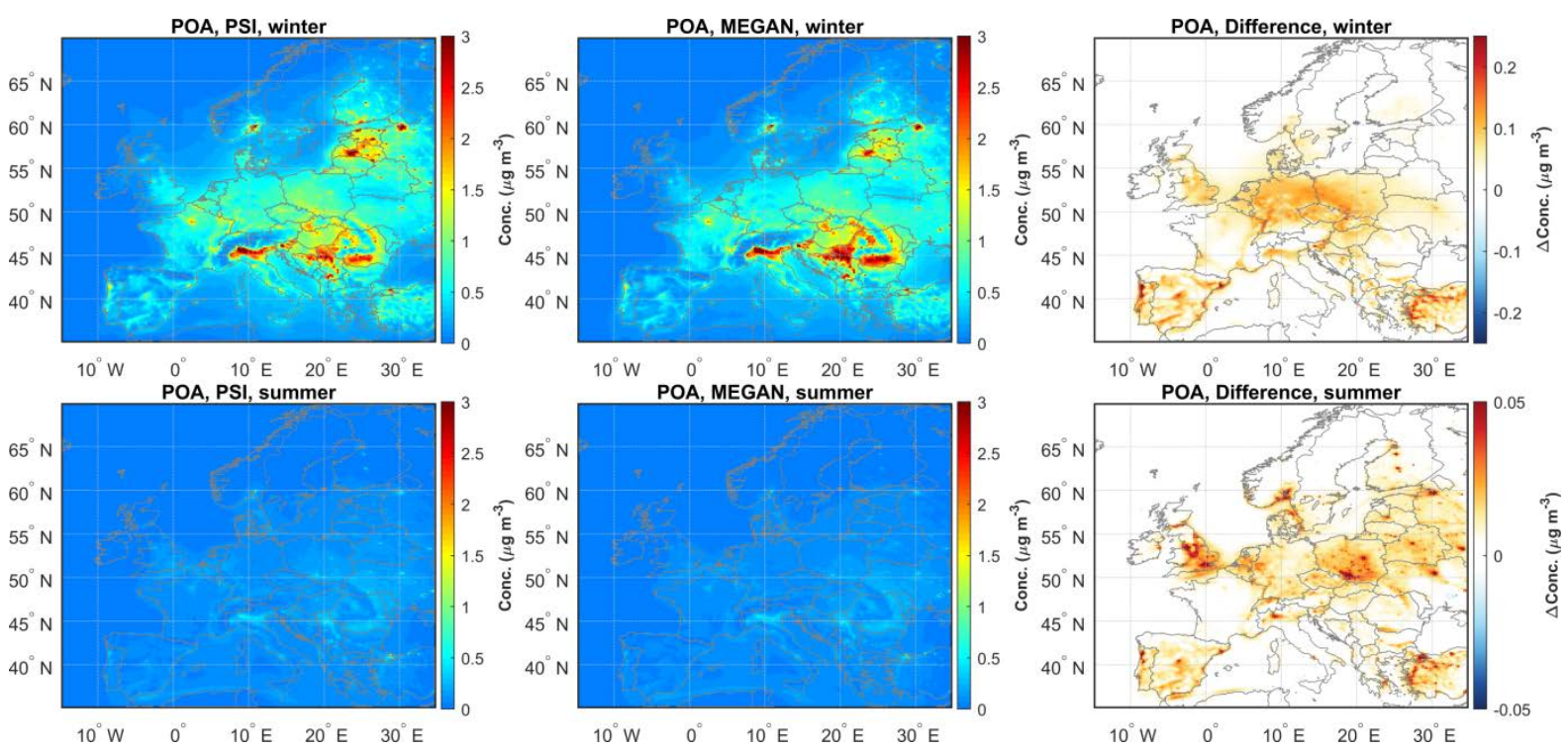

Figure S6. Modelled POA concentrations using BVOCs emission input by PSI Model (left panel) and MEGAN v2.1 (middle panel) and their difference (PSI - MEGAN, in right panel). 

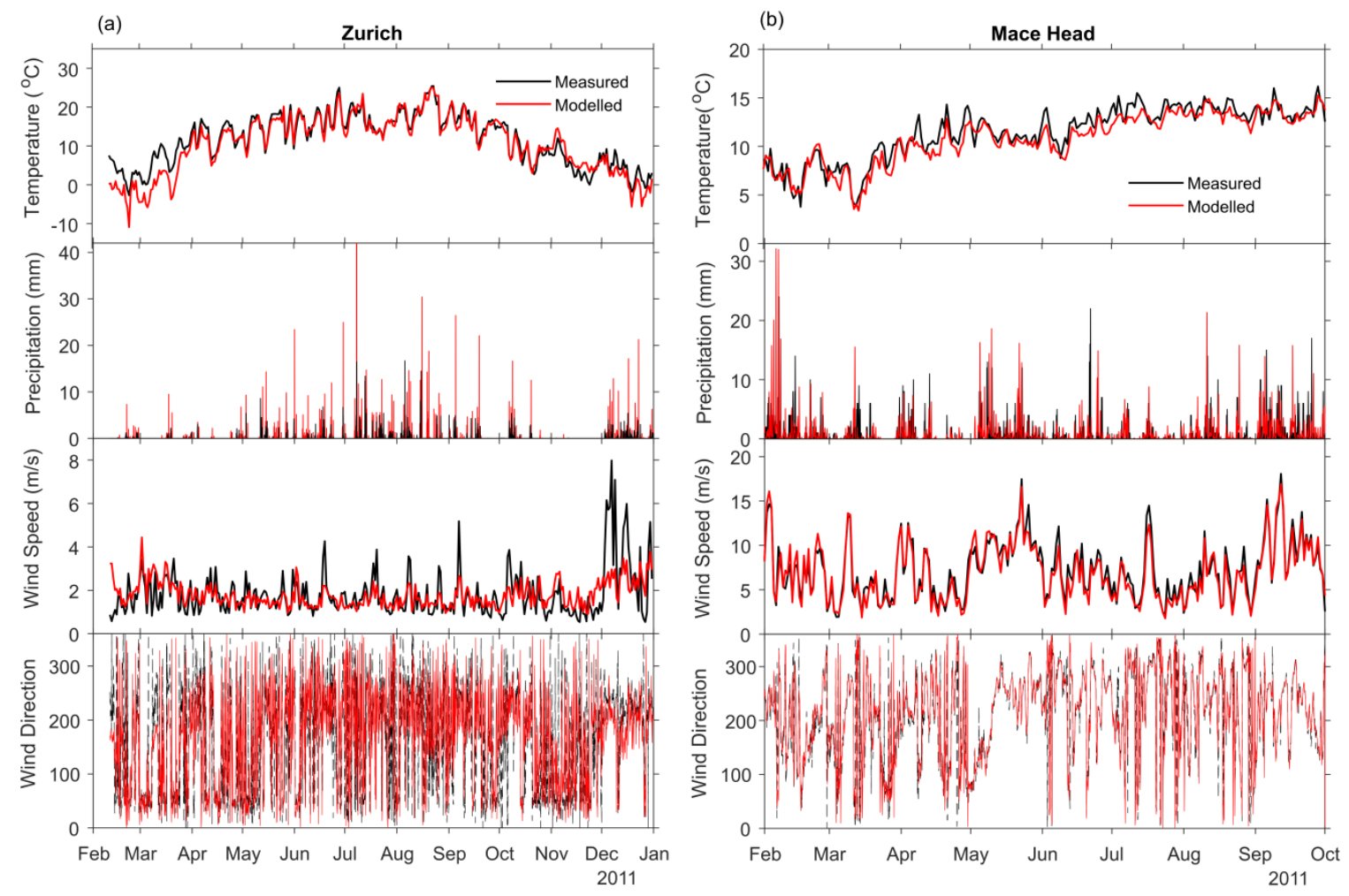

Figure S7. Comparison of observed and modelled temperature $\left({ }^{\circ} \mathrm{C}\right)$, hourly precipitation $(\mathrm{mm})$, wind speed (m/s) and wind direction (degree) at Zurich and Mace Head. Hourly observation data for Zurich was obtained from the automatic monitoring network of MeteoSwiss (ANETZ). Observed temperature, wind speed and wind direction at Mace Head were from Meteireann weather station, which is $~ 300$ meters away from the AMS station; while measured precipitation at Mace Head was obtained from Belmullet, a coastal station close to Mace Head, which was downloaded from the UK Met Office Integrated Data Archive System (MIDAS) Land Surface Stations database (Meteorological Office, 2013), and with 3-hour time intervals. 


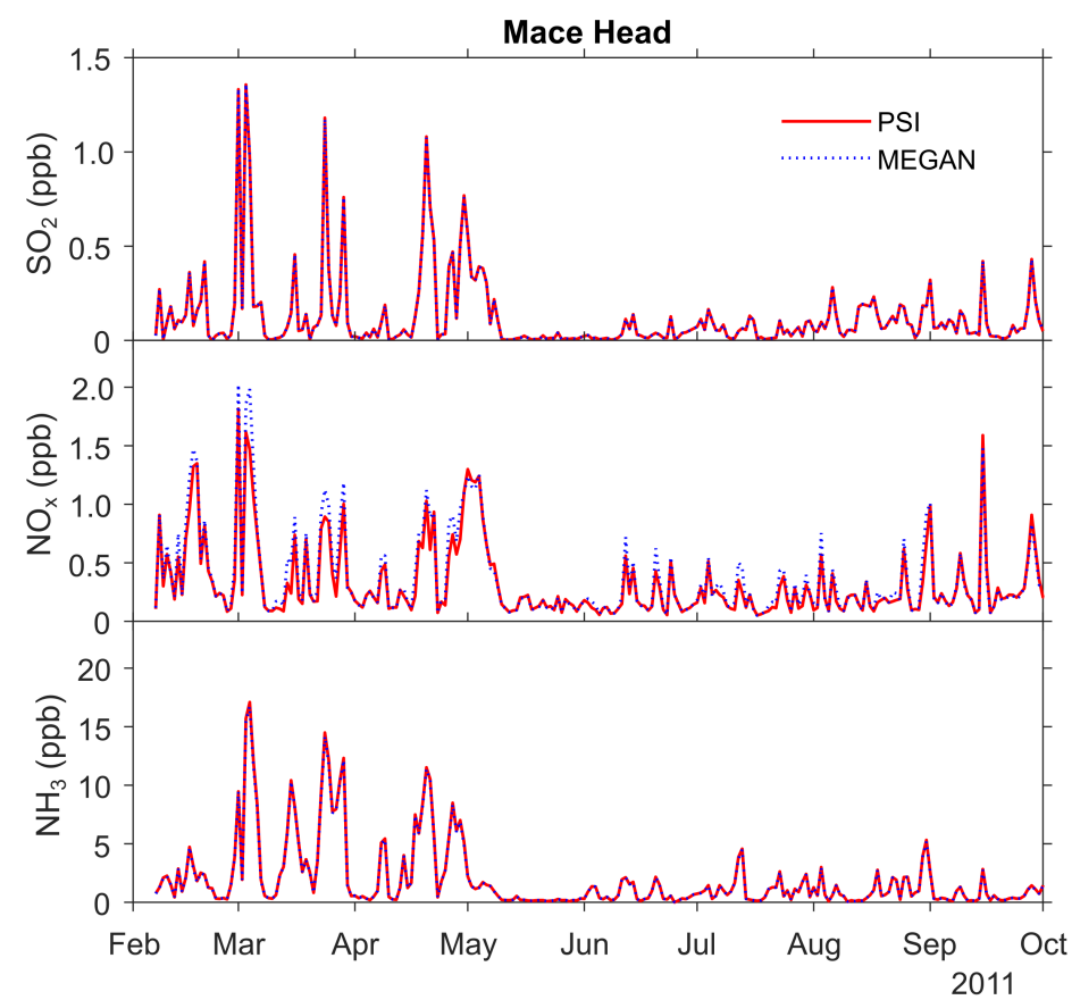

Figure S8. Temporal variation of the modelled (with both PSI and MEGAN emissions) $\mathrm{SO}_{2}, \mathrm{NO}_{\mathrm{x}}$ and $\mathrm{NH}_{3}$ at Mace Head in 2011.
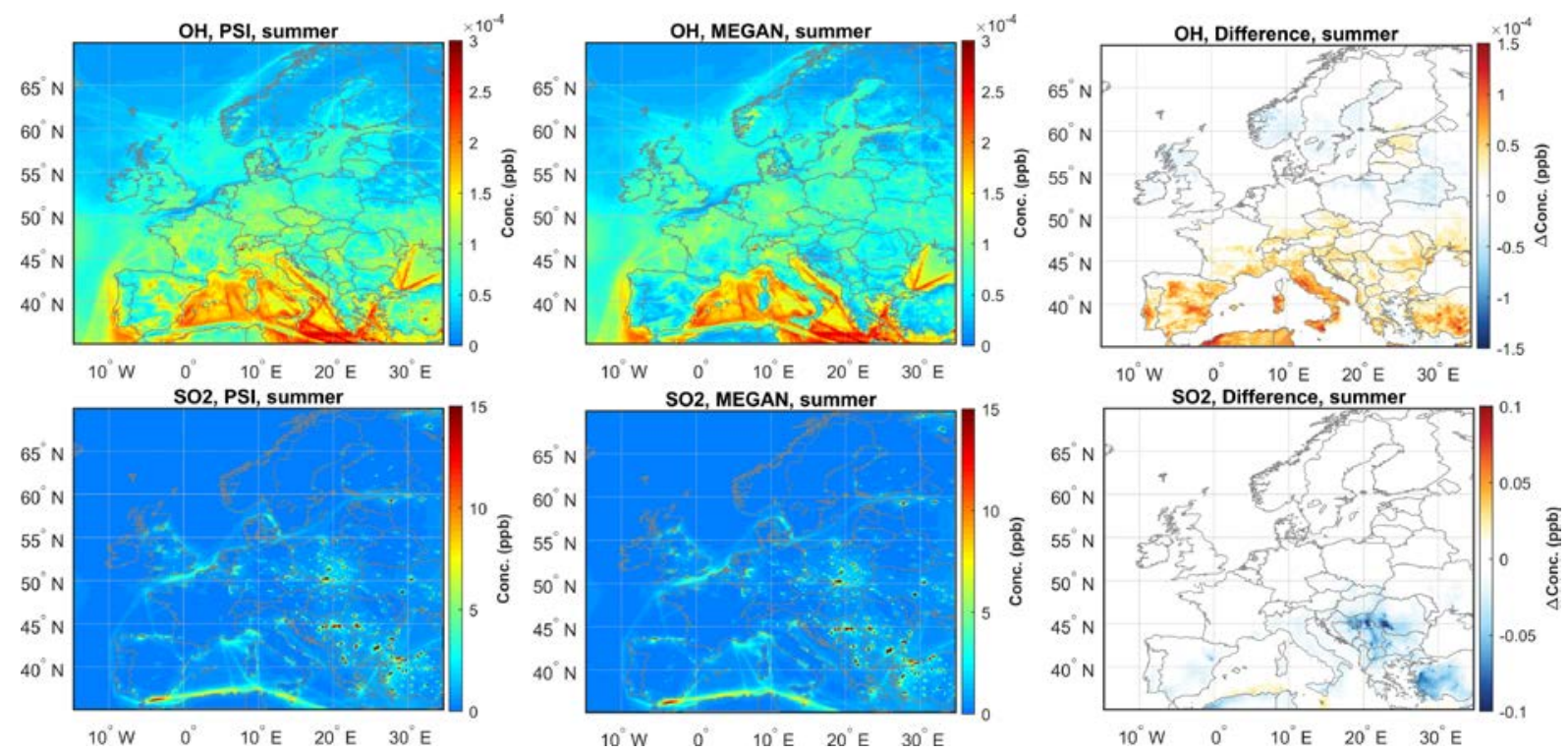

Figure S9. Modelled $\mathrm{OH}$ and $\mathrm{SO}_{2}$ concentrations using PSI emissions (left), MEGAN emissions (middle) and the difference between them (right). 